\title{
Lifestyle Interventions for Polycystic Ovary Syndrome: Cross-Sectional Survey to Assess Women's Treatment and Outcome Preferences
}

Laura R Saslow ${ }^{1}, \mathrm{PhD}$; James E Aikens ${ }^{2}, \mathrm{PhD}$

${ }^{1}$ Department of Health Behavior and Biological Sciences, School of Nursing, University of Michigan, Ann Arbor, MI, United States

${ }^{2}$ Department of Family Medicine, University of Michigan, Ann Arbor, MI, United States

Corresponding Author:

Laura R Saslow, $\mathrm{PhD}$

Department of Health Behavior and Biological Sciences

School of Nursing

University of Michigan

Room 2178, 400 N Ingalls Street

Ann Arbor, MI, 48109

United States

Phone: 17347647836

Email: saslowl@umich.edu

\section{Abstract}

Background: Polycystic ovary syndrome (PCOS) is the most common endocrine disorder in women of reproductive age. Diet and lifestyle programs improve health, but women's preferences for these programs have not been formally explored.

Objective: The aim of our study was to examine diet and lifestyle program preferences among women with PCOS.

Methods: We conducted a cross-sectional online survey of women with PCOS.

Results: At least half of the 197 respondents expressed strong interest in programs addressing energy level, anxiety, depression, weight, diabetes prevention, menstrual period regulation, and hirsutism. Similarly, at least half reported willingness to modify their sleep, stress, and physical activity; and slightly less than half reported willingness to adopt a very low-carbohydrate, paleo, or low-glycemic index diet. At least half reported interest in online or mobile programs and email-based mentoring. Younger age was associated with interest in help with acne and fertility; higher body mass index was associated with wanting help with weight loss, energy, and anxiety; and greater stress eating was associated with wanting help with depression, anxiety, and menstrual period regulation.

Conclusions: To our knowledge, this is the first study to examine attitudes and preferences of women with PCOS toward such programs. Future online and mobile diet and lifestyle programs may be able to capitalize on this information to better target this population's expressed preferences.

(JMIR Form Res 2020;4(9):e17126) doi: 10.2196/17126

\section{KEYWORDS}

polycystic ovary syndrome; lifestyle intervention; online and mobile; health psychology; nutrition

\section{Introduction}

Polycystic ovary syndrome (PCOS) is the most common endocrine disorder in women of reproductive age. Women with it often experience obesity, insulin resistance, hyperinsulinemia, infertility, and clinical manifestations of hyperandrogenism (chronic anovulation, hirsutism, and acne) as well as have a higher risk for cardiovascular disease and type 2 diabetes [1,2].
Women with PCOS can face other challenges. On average, they experience higher levels of depressive [3] and anxiety symptoms [4], which, when elevated, may increase their use of maladaptive coping strategies such as escape-avoidance coping (wishful thinking or behavior to avoid a problem) and lower levels of adaptive coping such as planful problem solving and positive reappraisal (focusing on positive meaning and growth) [5]. They may feel abnormal and less feminine because many of their symptoms, such as hirsutism and infertility, are not traditionally 
emblematic of femininity [6] and because the popular press often depicts them as less able to fulfill their roles as wives and mothers [7]. On the other hand, online discussion boards and in-person support groups may be able to provide them socioemotional and informational social support [8,9].

The Androgen Excess and PCOS Society calls for the primary treatment of metabolic complications for women with PCOS to be through diet and lifestyle programs $[10,11]$. Similarly, the Endocrine Society encourages these interventions for overweight or obese women with PCOS [12]. Thus, diet and lifestyle programs should be playing a central role in treating women with PCOS. However, previous trials of PCOS diet and lifestyle interventions have had high dropout rates [13-15].

These high dropout rates [13-15] have been related to various factors. For example, participants who dropped out had higher baseline testosterone [16], insulin resistance [14], or weight [14] than those of participants who completed the intervention. Moreover, women with PCOS tend to be younger than participants in typical weight loss programs, and younger women tend to have higher dropout rates generally [17].

Therefore, we aimed to extend the impact and retention of future PCOS diet and lifestyle programs by surveying women with PCOS about their program preferences. Thus, a goal of this research was to provide valuable data that can be used to inform future intervention development for symptom management and disease prevention among women with PCOS.

\section{Methods}

\section{Setting and Participants}

We solicited feedback from women who had been diagnosed with PCOS using an online survey website-Amazon Mechanical Turk. This allowed us to survey women anonymously while still paying them for their participation. We described that, "this survey is for women with Polycystic Ovary Syndrome (PCOS) who might be interested in a diet and lifestyle program to help improve their health... If you don't have PCOS do not continue." Thus, this was a self-qualified convenience sample.
Participants provided informed consent online. The research was approved by the University of Michigan Institutional Review Board (HUM00127004).

\section{Measures}

Participants used a 7-point Likert scale (1=not very interested to 7=very interested) to rate their interest in a diet and lifestyle program to achieve each of 9 health outcomes [18] using each of 7 potential program format options $[19,20]$. They also rated their willingness to make 6 diet and lifestyle changes [21-25] using a 7 -point scale (1=not at all willing to $7=$ very willing). We measured stress-related eating using the 4-item Eating to Cope subscale of the Palatable Eating Motives Scale (PEMS) [26], which asks people to consider what reasons people give for eating highly palatable foods such as sweets, salty snacks, fast foods, and sugary drinks, rated on a 5-point scale (almost never/never, some of the time, half of the time, most of the time, almost always/always). The 4 prompts include "to forget your worries," "because it helps you when you feel depressed or nervous," "to cheer up when you are in a bad mood," and "to forget about your problems." We also asked participants 2 open-ended questions about their PCOS and possible programs: "What health concerns do you have related to it?" and "What other aspects of a diet and lifestyle program might be useful?"

\section{Statistical Analyses}

Descriptive data are presented in means, standard deviations, and percentages. We dichotomously classified interest responses of at least 6 out of 7 as "interested" and willingness ratings of at least 6 out of 7 as "willing." We computed associations between selected predictors (body mass index or BMI, age, education, and PEMS) and continuous ratings of interest and willingness. Given the exploratory nature of the study, we tested Pearson correlations using a conservative criterion of $P<.01$.

\section{Results}

We recruited 197 women with self-identified PCOS. See Table 1 for sample characteristics. 
Table 1. Baseline characteristics of women with PCOS (N=197).

\begin{tabular}{|c|c|}
\hline Characteristics & Values \\
\hline Age in years, mean (SD) & $32.8(8.1)$ \\
\hline \multicolumn{2}{|l|}{ Race/ethnicity, n (\%) } \\
\hline Asian/Pacific Islander & $8(4.1)$ \\
\hline Black & $16(8.1)$ \\
\hline White & $173(87.8)$ \\
\hline American Indian or Alaskan Native & $10(5.1)$ \\
\hline Latino & $22(11.2)$ \\
\hline \multicolumn{2}{|l|}{ Education level, n (\%) } \\
\hline Not a college graduate & $79(40.1)$ \\
\hline College graduate & $85(43.1)$ \\
\hline Post graduate education & $33(16.8)$ \\
\hline \multicolumn{2}{|l|}{ Total household income, n (\%) } \\
\hline Up to US $\$ 35,000$ & $63(32.0)$ \\
\hline US $\$ 35,001$ - US $\$ 75,000$ & $99(50.3)$ \\
\hline Over US $\$ 75,000$ & $35(17.8)$ \\
\hline Years since diagnosis of PCOS ${ }^{\mathrm{a}}$ years, mean (SD) & $6.9(6.6)$ \\
\hline Weight in kg, mean (SD) & $81.2(26.1)$ \\
\hline Body Mass Index in $\mathrm{kg} / \mathrm{m}^{2}$, mean (SD) & $29.6(9.7)$ \\
\hline Stress eating, ${ }^{b}$ mean $(\mathrm{SD})$ & $2.7(1.2)$ \\
\hline
\end{tabular}

${ }^{\text {a} P C O S: ~ p o l y c y s t i c ~ o v a r y ~ s y n d r o m e . ~}$

${ }^{\mathrm{b}}$ Scores on Eating to Cope subscale of the Palatable Eating Motives Scale (PEMS).

\section{Potential Program Outcomes}

Between $53 \%$ and $73 \%$ of respondents reported interest in a program that would help them to feel more energetic, feel less anxious and depressed, lose weight, prevent a diabetes onset, regulate menstrual periods, and reduce hirsutism (Table 2).

The older the women were, the more interested they were in increasing their energy and preventing diabetes, but the less they were interested in reducing acne and becoming pregnant.
The more overweight the women were, the more interested they were in increasing their energy, reducing their anxiety, losing weight, preventing diabetes, and reducing hirsutism. Greater stress eating was associated with interest in reducing anxiety and depression as well as regulating menstrual periods.

We also asked respondents to report any other health concerns they had about PCOS using an open-ended question. These responses included pain, thinning hair, mood swings, and loss of libido. 
Table 2. Associations between interest/willingness ratings in potential program features and selected respondent variables.

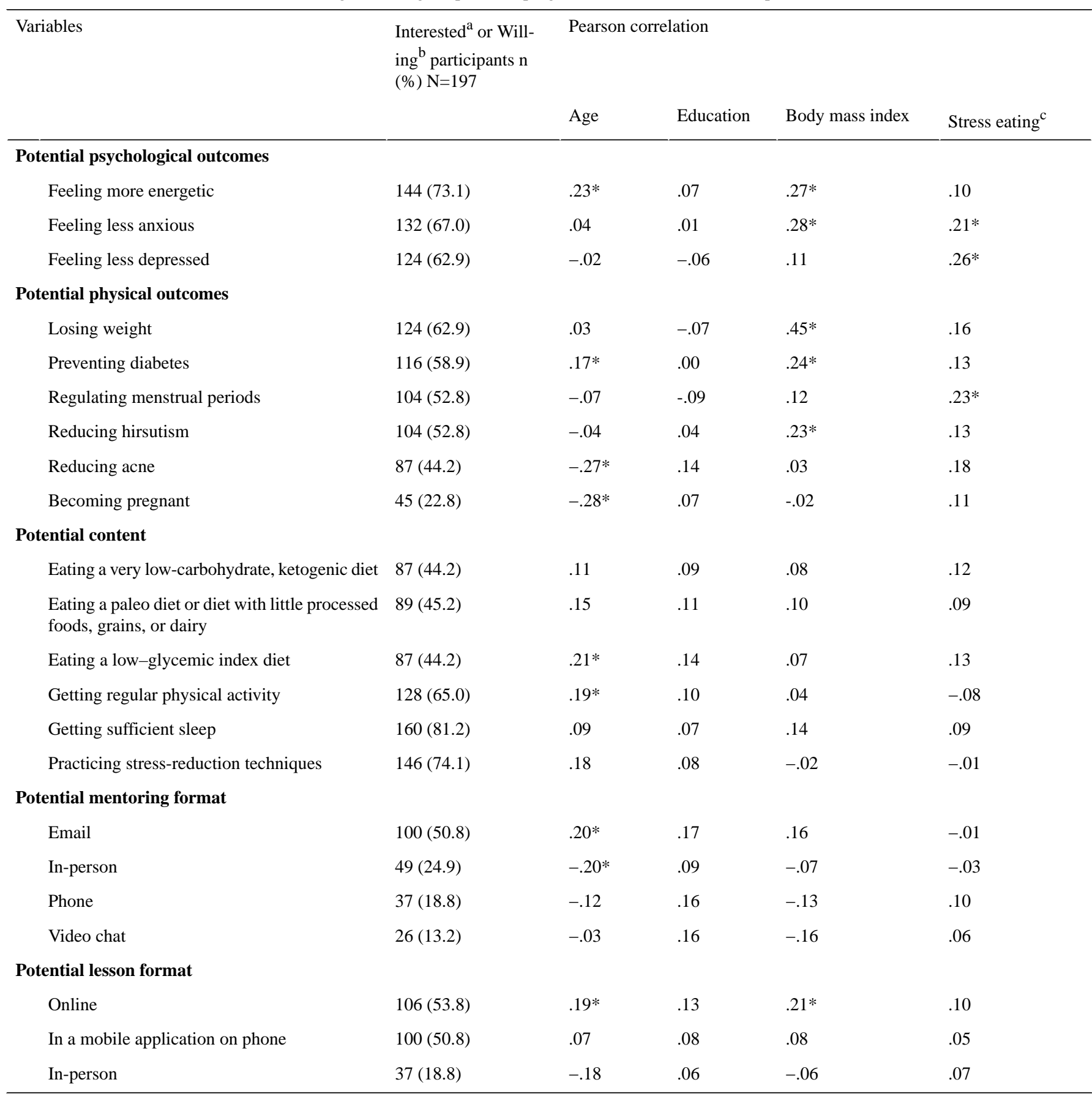

$* P<.01$.

${ }^{\mathrm{a}}$ Response of at least 6 out of 7 on interest scale.

${ }^{b}$ Response of at least 6 out of 7 on willingness scale.

${ }^{\mathrm{c}}$ Eating to Cope subscale of the Palatable Eating Motives Scale (PEMS).

\section{Program Content (Behavior Change Targets)}

Between $65 \%$ to $81 \%$ of respondents reported a willingness to get regular physical activity and sufficient sleep as well as a willingness to practice stress-reduction techniques (Table 2). Only 44\%-45\% were willing to try each of the 3 diets. Older age was correlated with a willingness to try a low-glycemic index diet and get regular physical activity. Weight, education, and stress eating were not correlated with a willingness to change any of the behaviors.

\section{Program Format}

Between $51 \%$ to $54 \%$ of respondents were interested in receiving help from a mentor via email, online lessons, or mobile lessons. In contrast, one-fourth or less were interested in receiving mentorship in person, by telephone, or via video chat; and less than one-fifth were interested in in-person lessons. Age was positively associated with interest in being mentored over email and receiving online lessons, and negatively associated with being mentored in person. BMI was positively associated with 
interest in receiving online lessons. Education and stress eating were not correlated with any program format preferences.

Using an open-ended question, we also asked participants what other aspects of a diet and lifestyle program might be useful. They described other possible features, including getting support from a coach ("just having a person who is there for you"); peers ("I think the support of others going through the same thing could be very meaningful"); or generally anyone supportive ("Constant reassurance would be the most useful tool"). They wanted this support to help keep them accountable to their goals. Participants suggested that the program provide reminders of their goals and rewards for reaching those goals. Some mentioned wanting mobile applications or online or text-based interactions ("Daily goals/reminders through push notifications on a mobile app," and "I just like accountability without having to talk on the phone or in person. I'm an introvert so I like online message boards, text messages, etc.") whereas others wanted in-person help ("I would rather just have a checklist of things to do, like a hard copy piece of paper that I can hang on my fridge to help guide my food choices and remind me why those choices are important" and "I like meeting a person in real life because you can see and feel the motivation from them").

\section{Discussion}

This study aimed to determine which diet and lifestyle program features appeal to women with PCOS. Results suggest that the majority of women prefer programs targeting numerous outcomes, including increasing energy, reducing anxiety and depression, losing weight, lowering diabetes risk, regulating menstruation, and reducing hirsutism. A clear majority were interested in a topical coverage of sleep, stress reduction, and physical activity. There were lower rates of interest in various diets. Finally, about half of the survey respondents expressed interest in email-based mentoring and online or mobile delivery.

Findings could also inform efforts to maximize program appeal to various PCOS subgroups. For example, the younger the women were, the more interested they were in typical concerns of younger women, including reducing acne and increasing fertility. Further, the higher a woman's BMI, the more she preferred a program to help with weight loss, improved energy, and reduced anxiety.

To our knowledge, this is the first study to examine program attitudes and preferences in this population. However, a primary study limitation is the online recruitment of a convenience sample. This may at least partially explain reported preferences for online or mobile programs and email-based mentoring. Additionally, self-report biases such as social desirability may have affected respondents' ratings of interest and willingness. Nonetheless, future online and mobile diet and lifestyle programs may be able to capitalize on this information to better target this population's expressed preferences.

Overall, we hope that this research can help inform future diet and lifestyle programs for women with PCOS. Ideally, this will enable the programs to have fewer participants who drop out of the programs and more satisfied and adherent participants.

\section{Acknowledgments}

We thank all of the women who participated in this research. LRS was supported by funding from the National Institutes of Health - a K01 from the National Institute of Diabetes and Digestive and Kidney Diseases (DK107456). The funder had no role in study design, data collection and analysis, decision to publish, or preparation of the manuscript.

\section{Conflicts of Interest}

None declared.

\section{References}

1. Rotterdam ESHRE/ASRM-Sponsored PCOS Consensus Workshop Group. Revised 2003 consensus on diagnostic criteria and long-term health risks related to polycystic ovary syndrome. Fertil Steril 2004 Jan;81(1):19-25. [doi: 10.1016/j.fertnstert.2003.10.004] [Medline: 14711538]

2. de Groot PCM, Dekkers OM, Romijn JA, Dieben SWM, Helmerhorst FM. PCOS, coronary heart disease, stroke and the influence of obesity: a systematic review and meta-analysis. Hum Reprod Update 2011;17(4):495-500. [doi: 10.1093/humupd/dmr001] [Medline: 21335359]

3. Dokras A, Clifton S, Futterweit W, Wild R. Increased risk for abnormal depression scores in women with polycystic ovary syndrome: a systematic review and meta-analysis. Obstet Gynecol 2011 Jan;117(1):145-152. [doi: 10.1097/AOG.0b013e318202b0a4] [Medline: 21173657]

4. Dokras A, Clifton S, Futterweit W, Wild R. Increased prevalence of anxiety symptoms in women with polycystic ovary syndrome: systematic review and meta-analysis. Fertil Steril 2012 Jan;97(1):225-30.e2. [doi: 10.1016/j.fertnstert.2011.10.022] [Medline: 22127370]

5. Carron R, Kooienga S, Boyle DK, Alvero R. Coping in Women With Polycystic Ovary Syndrome: Implications for Practitioners. The Journal for Nurse Practitioners 2017 Nov;13(10):700-707. [doi: 10.1016/i.nurpra.2017.08.004]

6. Kitzinger C, Willmott J. 'The thief of womanhood': women's experience of polycystic ovarian syndrome. Soc Sci Med 2002 Feb;54(3):349-361. [doi: 10.1016/s0277-9536(01)00034-x] [Medline: 11824912]

7. Sanchez N, Jones H. "Less Than A Wife": A Study of Polycystic Ovary Syndrome Content in Teen and Women's Digital Magazines. J Med Internet Res 2016 Jun 02;18(6):e89 [FREE Full text] [doi: 10.2196/jmir.5417] [Medline: 27255809] 
8. Holbrey S, Coulson NS. A qualitative investigation of the impact of peer to peer online support for women living with polycystic ovary syndrome. BMC Womens Health 2013 Dec 17;13:51 [FREE Full text] [doi: 10.1186/1472-6874-13-51] [Medline: 24341398]

9. Percy C, Gibbs T, Potter L, Boardman S. Nurse-led peer support group: experiences of women with polycystic ovary syndrome. J Adv Nurs 2009 Oct;65(10):2046-2055. [doi: 10.1111/j.1365-2648.2009.05061.x] [Medline: 19686401]

10. Moran LJ, Pasquali R, Teede HJ, Hoeger KM, Norman RJ. Treatment of obesity in polycystic ovary syndrome: a position statement of the Androgen Excess and Polycystic Ovary Syndrome Society. Fertil Steril 2009 Dec;92(6):1966-1982. [doi: 10.1016/j.fertnstert.2008.09.018] [Medline: 19062007]

11. Wild RA, Carmina E, Diamanti-Kandarakis E, Dokras A, Escobar-Morreale HF, Futterweit W, et al. Assessment of cardiovascular risk and prevention of cardiovascular disease in women with the polycystic ovary syndrome: a consensus statement by the Androgen Excess and Polycystic Ovary Syndrome (AE-PCOS) Society. J Clin Endocrinol Metab 2010 May;95(5):2038-2049. [doi: 10.1210/jc.2009-2724] [Medline: 20375205]

12. Legro RS, Arslanian SA, Ehrmann DA, Hoeger KM, Murad MH, Pasquali R, Endocrine Society. Diagnosis and treatment of polycystic ovary syndrome: an Endocrine Society clinical practice guideline. J Clin Endocrinol Metab 2013 Dec;98(12):4565-4592 [FREE Full text] [doi: 10.1210/jc.2013-2350] [Medline: 24151290]

13. Hoeger KM, Kochman L, Wixom N, Craig K, Miller RK, Guzick DS. A randomized, 48-week, placebo-controlled trial of intensive lifestyle modification and/or metformin therapy in overweight women with polycystic ovary syndrome: a pilot study. Fertil Steril 2004 Aug;82(2):421-429. [doi: 10.1016/j.fertnstert.2004.02.104] [Medline: 15302293]

14. Marsh K, Steinbeck KS, Atkinson FS, Petocz P, Brand-Miller JC. Effect of a low glycemic index compared with a conventional healthy diet on polycystic ovary syndrome. Am J Clin Nutr 2010 Jul;92(1):83-92. [doi: 10.3945/ajcn.2010.29261] [Medline: 20484445]

15. Turner-McGrievy GM, Davidson CR, Wingard EE, Billings DL. Low glycemic index vegan or low-calorie weight loss diets for women with polycystic ovary syndrome: a randomized controlled feasibility study. Nutr Res 2014 Jun;34(6):552-558. [doi: 10.1016/j.nutres.2014.04.011] [Medline: 25026923]

16. Kuchenbecker WKH, Groen H, van Asselt SJ, Bolster JHT, Zwerver J, Slart RHJ, et al. In women with polycystic ovary syndrome and obesity, loss of intra-abdominal fat is associated with resumption of ovulation. Hum Reprod 2011 Sep;26(9):2505-2512. [doi: 10.1093/humrep/der229] [Medline: 21771766]

17. Honas J, Early JL, Frederickson DD, O'Brien MS. Predictors of attrition in a large clinic-based weight-loss program. Obes Res 2003 Jul;11(7):888-894 [FREE Full text] [doi: 10.1038/oby.2003.122] [Medline: 12855759]

18. Cronin L, Guyatt G, Griffith L, Wong E, Azziz R, Futterweit W, et al. Development of a health-related quality-of-life questionnaire (PCOSQ) for women with polycystic ovary syndrome (PCOS). J Clin Endocrinol Metab 1998 Jun;83(6):1976-1987. [doi: 10.1210/jcem.83.6.4990] [Medline: 9626128]

19. Muñoz Obino KF, Aguiar Pereira C, Caron-Lienert RS. Coaching and barriers to weight loss: an integrative review. Diabetes Metab Syndr Obes 2017;10:1-11 [FREE Full text] [doi: 10.2147/DMSO.S113874] [Medline: 28096687]

20. Brouwer W, Kroeze W, Crutzen R, de Nooijer J, de Vries NK, Brug J, et al. Which intervention characteristics are related to more exposure to internet-delivered healthy lifestyle promotion interventions? A systematic review. J Med Internet Res 2011 Jan 06;13(1):e2 [FREE Full text] [doi: 10.2196/jmir.1639] [Medline: 21212045]

21. Washburn RA, Szabo AN, Lambourne K, Willis EA, Ptomey LT, Honas JJ, et al. Does the method of weight loss effect long-term changes in weight, body composition or chronic disease risk factors in overweight or obese adults? A systematic review. PLoS One 2014;9(10):e109849 [FREE Full text] [doi: 10.1371/journal.pone.0109849] [Medline: 25333384]

22. Gower BA, Chandler-Laney PC, Ovalle F, Goree LL, Azziz R, Desmond RA, et al. Favourable metabolic effects of a eucaloric lower-carbohydrate diet in women with PCOS. Clin Endocrinol (Oxf) 2013 Oct;79(4):550-557. [doi: 10.1111/cen.12175] [Medline: 23444983]

23. Mavropoulos J, Yancy WS, Hepburn J, Westman EC. The effects of a low-carbohydrate, ketogenic diet on the polycystic ovary syndrome: a pilot study. Nutr Metab (Lond) 2005 Dec 16;2:35 [FREE Full text] [doi: 10.1186/1743-7075-2-35] [Medline: 16359551]

24. Domecq J, Prutsky G, Mullan RJ, Hazem A, Sundaresh V, Elamin MB, et al. Lifestyle modification programs in polycystic ovary syndrome: systematic review and meta-analysis. J Clin Endocrinol Metab 2013 Dec;98(12):4655-4663. [doi: 10.1210/jc.2013-2385] [Medline: 24092832]

25. Spiegel K, Tasali E, Leproult R, Van Cauter E. Effects of poor and short sleep on glucose metabolism and obesity risk. Nat Rev Endocrinol 2009 May;5(5):253-261 [FREE Full text] [doi: 10.1038/nrendo.2009.23] [Medline: 19444258]

26. Burgess E, Turan B, Lokken K, Morse A, Boggiano M. Profiling motives behind hedonic eating. Preliminary validation of the Palatable Eating Motives Scale. Appetite 2014 Jan;72:66-72. [doi: 10.1016/j.appet.2013.09.016] [Medline: 24076018]

\section{Abbreviations}

BMI: body mass index

PCOS: polycystic ovary syndrome

PEMS: Palatable Eating Motives Scale 


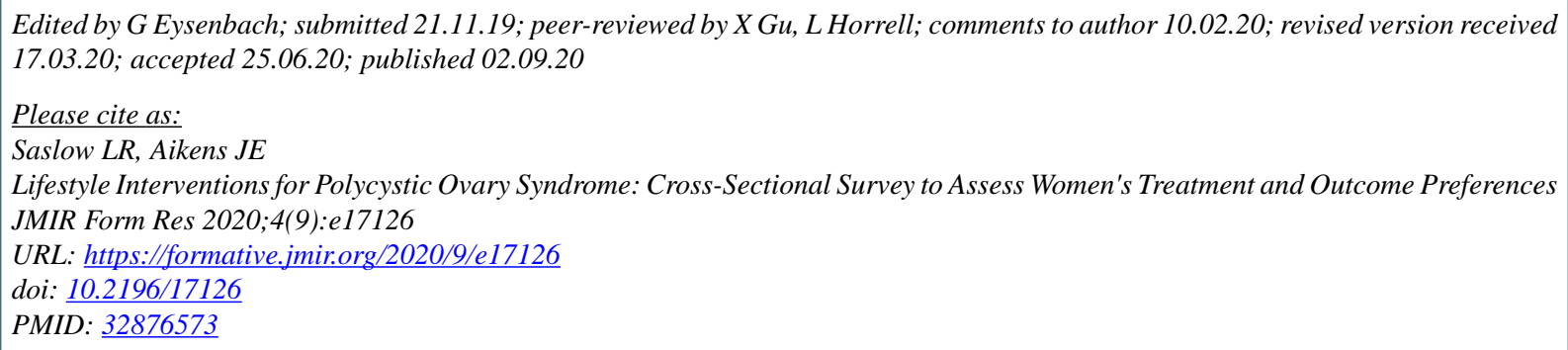

CLaura R Saslow, James E Aikens. Originally published in JMIR Formative Research (http://formative.jmir.org), 02.09.2020. This is an open-access article distributed under the terms of the Creative Commons Attribution License (https://creativecommons.org/licenses/by/4.0/), which permits unrestricted use, distribution, and reproduction in any medium, provided the original work, first published in JMIR Formative Research, is properly cited. The complete bibliographic information, a link to the original publication on http://formative.jmir.org, as well as this copyright and license information must be included. 